$$
231576
$$

UCRL-JC-128066

PREPRINT

\title{
Design of the Linear Non-Evaporable Getter Pump for the PEP-II B Factory
}

\author{
L. Bertolini \\ D. Behne \\ J. Bowman \\ D. Hathaway \\ K. Kishiyama \\ M. Mugge \\ T. Swan
}

This paper was prepared for submittal to the 1997 Particle Accelerator Conference

Vancouver, B. C., Canada

May 12-16, 1997

July 21, 1997

This is a preprint of a paper intended for publication in a journal or proceed inga. Since changes may be made before publication, this preprint is made available with the undertatending that it will not be cited or reproduced without the permisaion of the auther.

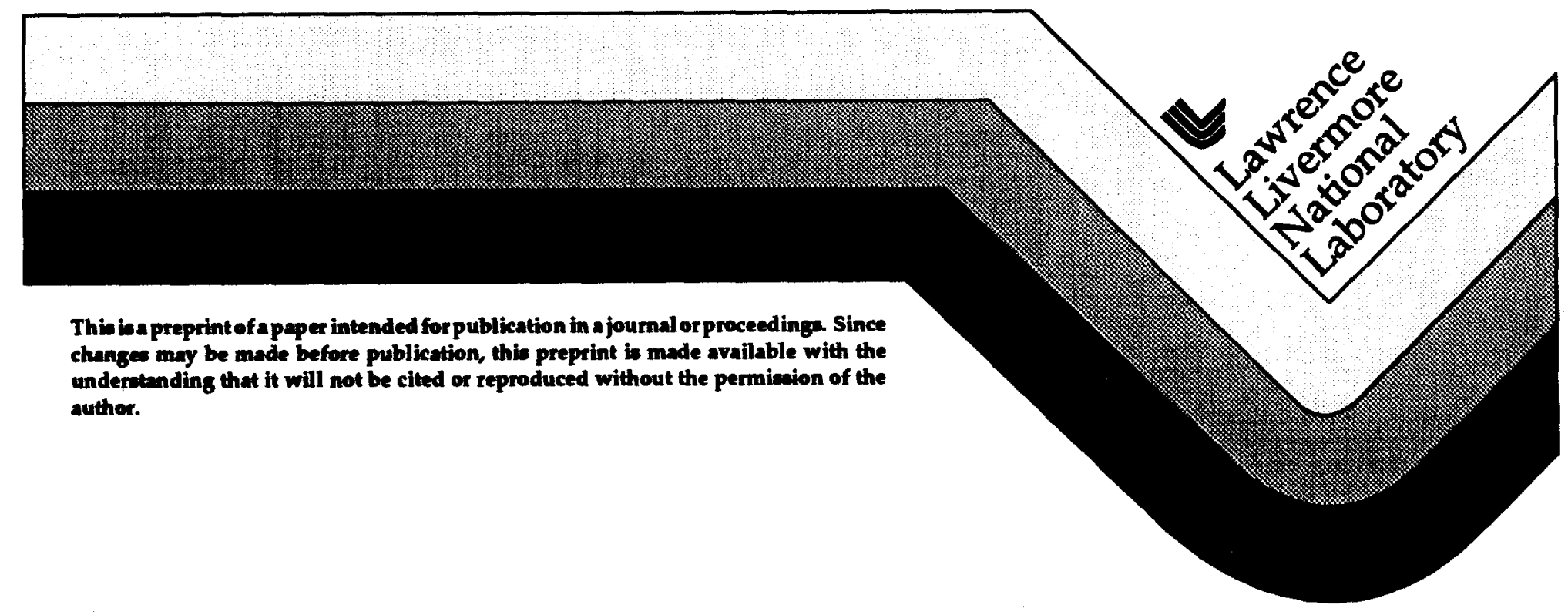




\section{DISCLAIMER}

This document was prepared as an account of work sponsored by an agency of the United States Government. Neither the United States Government nor the University of California nor any of their employees, makes any warranty, express or implied, or assumes any legal liability or responsibility for the accuracy, completeness, or usefulness of any information, apparatus, product, or process disclosed, or represents that its use would not infringe privately owned rights. Reference herein to any specific commercial product, process, or service by trade name, trademark, manufacturer, or otherwise, does not necessarily constitute or imply its endorsement, recommendation, or favoring by the United States Government or the University of Califormia. The views and opinions of authors expressed herein do not necessarily state or reflect those of the United States Government or the University of California, and shall not be used for advertising or product endorsement purposes. 


\title{
DESIGN OF THE LINEAR NON-EVAPORABLE GETTER PUMP FOR THE PEP-II $B$ FACTORY
}

\author{
L.Bertolini, D. Behne, J. Bowman, D. Hathaway, K. Kishiyama, M. Mugge, T.Swan \\ Lawrence Livermore National Laboratory, University of California, Livermore, CA 94550 USA
}

\begin{abstract}
There are several regions in the PEP-II $B$ Factory at SLAC that require distributed pumping to deal with large photo-desorbed gas loads or to produce very low pressures $\left(<10^{-9}\right.$ Torr). These regions include the Low Energy Ring Wiggler dump chambers, the transitions between the High Energy Ring arcs and straight sections, and most importantly the Interaction Region. We have designed a compact Non-Evaporable Getter pump using commercial getters that combines high pumping speed and high sorption capacity. We describe the design features of the NEG pumps, and our test results from prototype pumps. In addition, we discuss future variations of this style of NEG pump.
\end{abstract}

\section{INTRODUCTION}

The PEP-II Asymmetric B Factory collider is made up of two counter-circulating storage rings. The High Energy Ring (HER) circulates electrons at an energy of $9 \mathrm{GeV}$ and a current of 1 Amp. The Low Energy Ring circulates positrons at an energy of $3.1 \mathrm{GeV}$ and a current of 2.1 Amps. The Interaction Region (IR) vacuum system where the two beams collide requires very low average beamline pressures $\left(<10^{-9}\right.$ Torr). High gasloads generated by the synchrotron radiation striking the vacuum chamber walls necessitates a vacuum pumping system with high pumping speed and high sorption capacity. In addition, the low beamline conductance requires that the vacuum pumping be of a distributed or linear nature.

The vacuum pumping solution in the HER arcs is the Distributed Ion Pump (DIP). The HER arcs have 5.4 meter long dipole magnets to bend the electron beam in an arc. The DIPs conveniently make use of the residual magnetic field from the magnets to provide uniform distributed pumping along the beam aperture. DIPs however, are not a viable option in the Intraction Region. The pumping speed of ion pumps decreases as pressure decreases. In a region where sub-nTor pressures are the goal, this is not a desirable characteristic. In addition, the magnets in the IR do not provide enough coverage along the length of beamline to provide for continuous vacuum pumping.

Our solution is to use Non-evaporable Getters (NEG). The task is to configure the NEG in a way to maximize linear pumping speed and sorption capacity. The high pumping speed will produce the low beamline pressure we desire and the high sorption capacity will allow us to operate the NEGs for long periods of time before regenerating them. The NEG activation mechanism is also a concern. Activation by baking the chambers is not

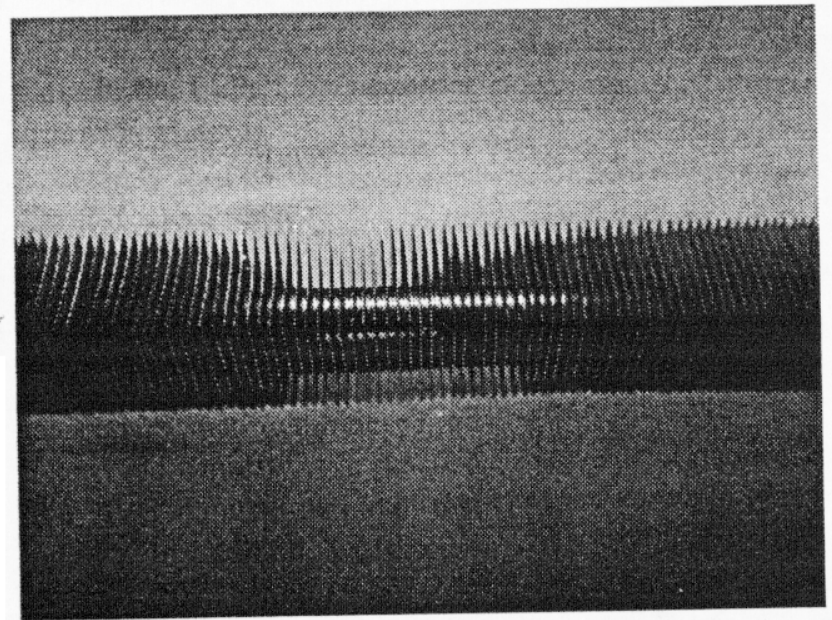

possible since the chambers are extruded half-hard, oxgen-free copper which will anneal at activation temperatures. Activation by ohmic heating requires continuous lengths of NEG and presents thermal expansion problems.

Two main concerns have been expressed about the use of NEGs within PEP-II. First, NEGs are inherently "dusty" devices to install into a high current electron storage ring. There was concern that the phenomena experienced at the HERA storage ring would occur at PEP-II. HERA experienced beam interactions with "macro-particles" which caused severely shortened beam lifetimes. The second concern was that high gas loads would result in unreasonably short regeneration intervals.

Once we developed an acceptable getter configuration, we found other regions within PEP-II where the NEG pump design could be applied. Figure 1 shows a plan view of PEP-II with the NEG locations identified. The PEP-II NEG pump design is used in the IR, the LER Wiggler vacuum chamber, and the HER arc-to-straight transition chambers.

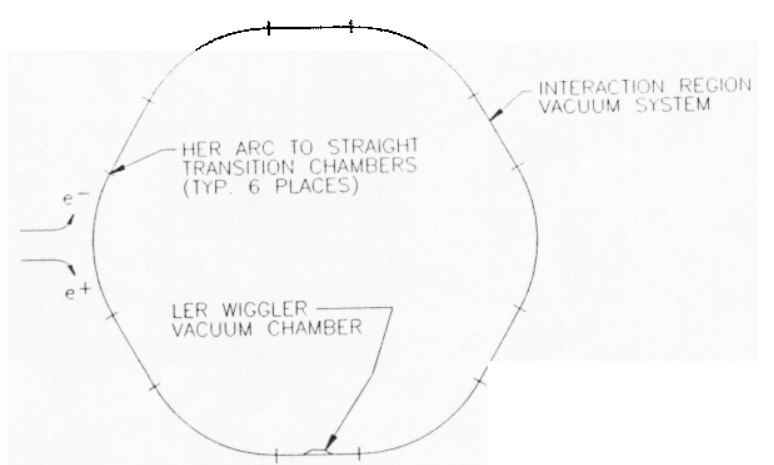

Figure 1. NEG Pump Locations within the PEP-II $B$ Factory 


\section{PUMP DESCRIPTION}

The pumping speed and sorption capacity of a NEG pump are proportional to the surface area of NEG material in the pump. For this reason it was important to find a way to maximize the surface area within the small volumes allocated for pumps in the beam tubes. We have decided to increase surface area in the same manner an engineer increases convective heat transfer area in a automobile radiator, by using "fins". We cut individual "wafers" from SAES ST707/CTAM/30D strip using a laser welding machine. The laser is used to produce as clean a cut as possible. We found that precision shearing dies produced tom edges which tended to increase dust generation from the NEG. Cutting the NEG with the laser (under a nitrogen gas purge) produced a clean edge without damaging the nearby granules of getter alloy.

A cross-section of the pump is shown in Figure 2. Individual NEG wafers are strung on a 0.375 " o.d., 0.035 " wall stainless steel tube. Adjacent wafers are separated by stainless steel wire spacers. The width of the spacers can be varied to adjust the speed and capacity of the pump. Typically, the NEG spacing ranges from $0.040 "$ to 0.120 ". The stainless steel tube has a 0.125 " square key attached along its length. The purpose of the key is to prevent rotation of the square NEG wafers. On each end of the pump are slip-on tube clamps that keep the wafer array compressed. The stainless steel tube has a cap on one end and a conflat flange on the other end. The tube acts as both a support for the NEG wafers and part of the vacuum barrier. The pump is inserted into a pumping antechamber within a PEP-II vacuum chamber and bolts to a conflat flange on the end of the chamber. Figure 3 shows a cut-away view of a NEG pump installed in an IR vacuum chamber. There are supports located every 20" along the stainless steel tube which stand the pump off the walls of the antechamber. The supports and the NEG wafers are sized to allow a conflat gasket to be slipped over the pump to seal the end flange.

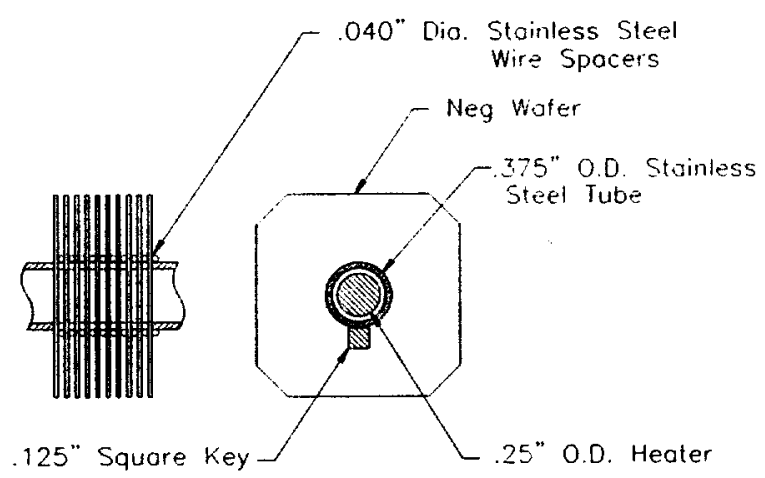

Figure 2. Cross-section of a PEP-II NEG Pump

Using a wafer spacing of $0.040^{\prime \prime}$, we have built vacuum pumps with the equivalent of 18 meters of NEG strip per meter of pump length. That quantity of NEG can sorb several Torr-liters of gas before needing to be regenerated. After machine commissioning, we are predicting that the NEG pumps will only require annual regeneration.

Activation of the NEG is accomplished with a 0.25 " o.d. commercial tubular heater. The heater is inserted into the stainless steel tube from outside of the vacuum system. With the heater outside the vacuum there is no need for an elecrical feedthrough. If a heater fails, it can be

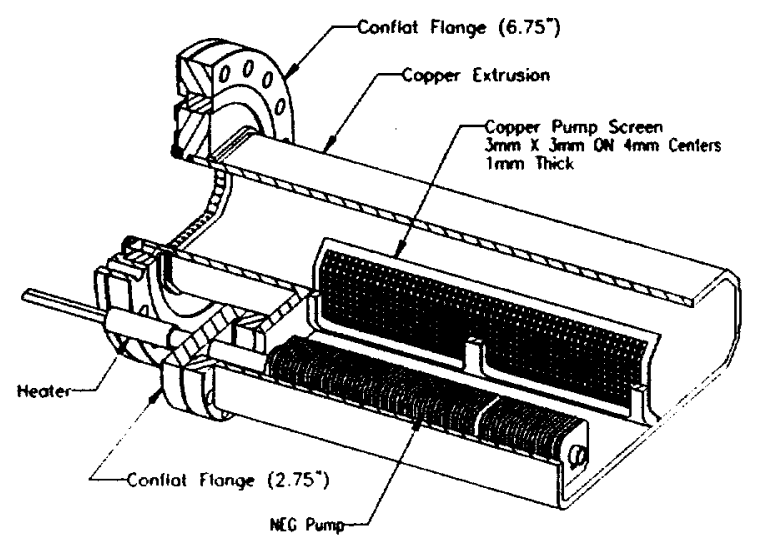

Figure 3. NEG Pump in an IR Chamber

replaced without venting the vacuum system. Since this pump is heated from the center there is a significant radial temperature variation across each wafer. For a 1.18" square wafer the temperature can vary as much as $180^{\circ} \mathrm{C}$. The published activation parameters for ST707 are $450^{\circ} \mathrm{C}$ for 45 minutes [1]. If we heat the NEG wafers to a minimum temperature of $450^{\circ} \mathrm{C}$ the center portion of each wafer will be approximately $600^{\circ} \mathrm{C}$. In previous activation tests [2] we have found the NEG alloy will suffer catastrophic delamination from the constantan substrate at approximately $710^{\circ} \mathrm{C}$. For this reason it is important to characterize the heater parameters well to avoid overheating and damaging the NEG.

\section{TESTING}

There were two goals in testing the prototype PEP-II NEG Pump. First of all we wanted to verify the pumping speed and sorption capacity of this new configuration. Sorption tests were conducted for prototype pumps with different wafer spacings. Figure 4 shows the sorption curve for a pump with 0.040" spaces between wafers. Also shown is a calculated sorption curve based on the NEG manufacturer's published data [1].

The second goal of the tests was to characterize the heater parameters required to adequately activate the NEG. Since the pumps installed in PEP-II will not be equipped with internal thermocouples it is essential that we know what heater parameters will produce the proper NEG temperature. The prototype pump was outfitted with two thermocouples, one on the outer edge of a NEG wafer and one attached to the outside of the stainless steel tube. Between sorption tests we activated the pumps and monitored the temperatures. Figure 5 shows the temperature profile of the NEG and stainless steel tube during a typical activation. 


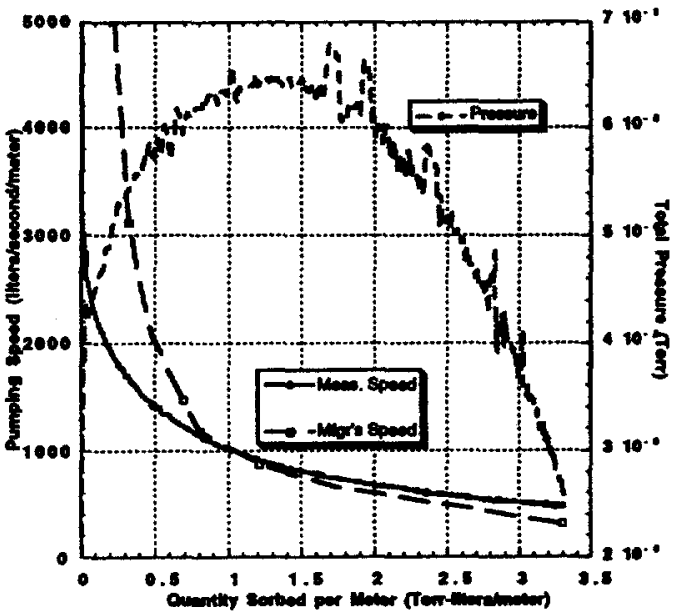

Figure 4. Sorption Curve for a PEP-II NEG Pump

\section{DUST}

There were two separate issues regarding "dust production" and NEGs. As we have mentioned earlier, we were concerned about the production of macroparticles that potentially could interact with the beams. But a second issue came up during the project. The European Synchrotron Radiation Laboratory (ESRF) experienced lifetime problems because of magnetic contaminants from ST707 interacting with their stored beam [3]. We not only worked to minimize dust production, but we also attempted to deal with magnetic dust production too. The best solution for both problems was to use a sintered NEG alloy. The alloys used in sintered configurations are not required to go through a ball mill where the magnetic contaminates are introduced. Sintering also produces much stronger adhesion than does the roll bonding process used on ST707 strip. Unfortunantly, the cost of the sintered NEGs was prohibitive for the project and therefore not an option. We were left with utilizing ST707 and trying to minimze dust production wherever possible. As mentioned earlier, we cut the individual NEG wafers with a laser to produce a clean edge. We also worked with SAES Getters S.p.A. to process all of our NEG by multiple passes through a magnetic sieve. These processes will not eliminate dust production, however, they may decrease it to an acceptable level. In chambers where our NEG pumps will experience changing magnetic fields, we may have to revisit sintered NEGs if we encounter problems.

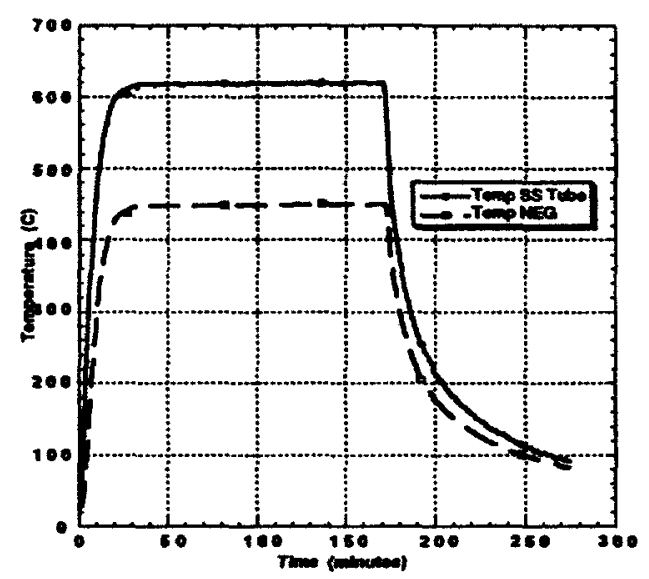

Figure 5. Temperature Plot of Typical NEG Activation

\section{SUMMARY}

We have designed a linear NEG pump to solve a variety of vacuum problems within the PEP-II machine. The pump utilizes an innovative configuration of commercial getter strips to produce high pumping speed an high sorption capacity. The pump design allows us to vary the quantity of getter and thus vary the linear pumping speed.

\section{ACKNOWLEDGEMENTS}

This work was supported by the Director, Office of Energy Research, Office of High Energy and Nuclear Physics Division, of the U.S. Department of Energy under contracts DE-AC03-76SF00098 and W-7405ENG-48-(LLNL).

\section{REFERENCES}

[1] SAES ST707 Product Data.

[2] "NEG Cyclic Tests," Holdener, Kishiyama, Mugge, and Stoeffel, LLNL, October 1994.

[3] "New Undulator Vacuum Chambers without Distributed Pumping," N. Rouviere, ESRF Newsletter, June 1995. 


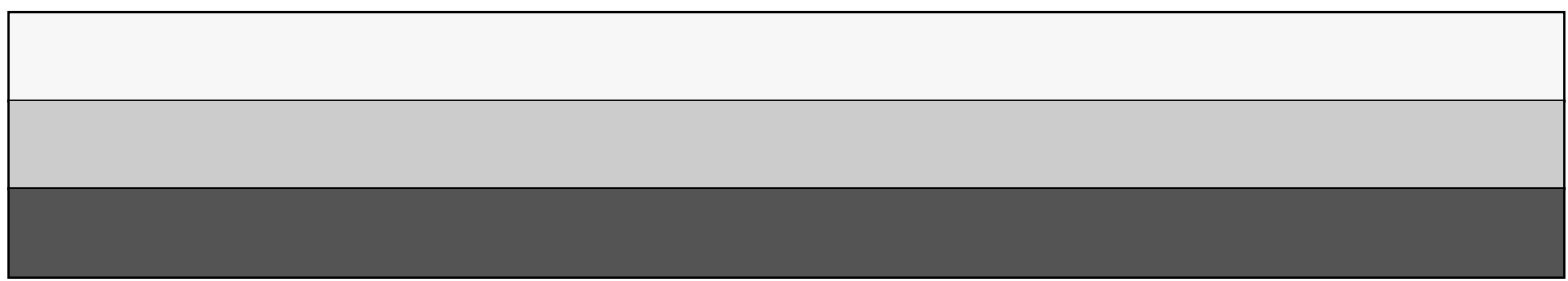

